Canadian

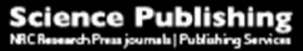

Botany

Botanique

\title{
Differences in early hyphal development of Podosphaera xanthii on Cucumis sativus leaves acclimatized to high or low relative humidity
}

\begin{tabular}{|r|l|}
\hline Journal: & Botany \\
\hline Manuscript ID & cjb-2017-0159.R1 \\
\hline Manuscript Type: & Note \\
\hline Date Submitted by the Author: & 04-Oct-2017 \\
\hline $\begin{array}{r}\text { Complete List of Authors: } \\
\text { Is the invited manuscript for } \\
\text { consideration in a Special } \\
\text { Issue? : }\end{array}$ & $\begin{array}{l}\text { Itagaki, Kaori; YANMAR Co., Ltd. } \\
\text { Shibuya, Toshio; Osaka Prefecture University, }\end{array}$ \\
\hline Keyword: & $\begin{array}{l}\text { cucurbit powdery mildew, leaf structure, plant-pathogen interactions, leaf } \\
\text { nitrogen content }\end{array}$ \\
\hline &
\end{tabular}

\section{SCHOLARONE"}

Manuscripts 
1 Differences in early hyphal development of Podosphaera xanthii on Cucumis sativus

2 leaves acclimatized to high or low relative humidity

3

$4 \quad$ Kaori Itagaki and Toshio Shibuya

5

6 Kaori Itagaki* and Toshio Shibuya. Graduate School of Life and Environmental Sciences,

7 Osaka Prefecture University, Gakuen-cho, Naka-ku, Sakai, Japan 599-8531.

8 *Present address: YANMAR Co., Ltd., Chayamachi, Kita-ku, Osaka, Japan 530-8311. E-

9 mail: kaori_itagaki@yanmar.com.

10

11 Corresponding author: Toshio Shibuya (e-mail: shibuya@envi.osakafu-u.ac.jp).

12 Graduate School of Life and Environmental Sciences, Osaka Prefecture University, Gakuen-

13 cho, Naka-ku, Sakai, Japan 599-8531.

14 Phone and Fax: +81-72-254-9433 
15 Abstract: This research investigated early hyphal development of cucurbit powdery mildew

16 (Podosphaera xanthii) on cucumber (Cucumis sativus L.) leaves acclimatized to different

17 relative humidities to clarify the factors that limit it. Cucumber seedlings were acclimatized to

18 a low $(10 \%)$ or high $(90 \%)$ relative humidity $(\mathrm{RH})$ at $30^{\circ} \mathrm{C}$ from germination. When the

19 cotyledons had expanded and the first true leaf had begun to emerge, plants were inoculated,

20 and initial conidial invasion, hyphal development, and secondary haustorial formation were

21 evaluated. The initial invasion of $P$. xanthii into the epidermis was slower on the low-RH

22 leaves than on the high-RH leaves, suggesting that structural properties, such as greater leaf

23 mass per area, physically limited the development of P. xanthii. The hyphal development and

24 secondary haustoria of conidia that had successfully infected the epidermis were also slower

25 on the low-RH leaves. These post-invasion behaviors indicate that conidial development was

26 also suppressed by non-structural properties of low-RH leaves such as nutrients which

27 correlate with non-structural defense. Reduced leaf $\mathrm{N}$ content of the low-RH leaves may in

28 part have inhibited the post-invasion behaviors of $P$. xanthii.

29

30 Key words. cucurbit powdery mildew, haustorium formation, initial invasion, leaf structure,

31 leaf nitrogen content, plant-pathogen interactions 


\section{3}

34

35

36

37

\section{Introduction}

Development of powdery mildews is influenced by atmospheric humidity, but response to humidity differs between different parts of the life cycle. The colonization, sporulation, and dispersal of powdery mildews are favored by low humidity (Yarwood 1957; Aust and v. Hoyningen-Huene 1986), whereas infection and survival are favored by high humidity (Reuveni and Rotem 1974). In addition to its direct effects on the pathogen, atmospheric humidity influences the host plants, which in turn influence the development of powdery mildew indirectly.

The authors previously reported that conidial development of cucurbit powdery mildew (Podosphaera xanthii) was suppressed on cucumber (Cucumis sativus L.) leaves acclimatized to low humidity (Itagaki et al. 2014). This previous research demonstrated that spore germination was not affected, but colony density and haustoria formation 7 days after inoculation were less on leaves whose epidermis had become thicker under lower humidity. Thus, the inhibition of $P$. xanthii development may have been due to changes in leaf structure, such as the thickness of epidermal cell wall. However, our knowledge of the early development of $P$. xanthii on leaves, which is important for understanding limitations on the infection process, is still incomplete.

The early development of $P$. xanthii after germination can be divided into initial invasion and subsequent development. The former can be limited by the structural properties of the host leaf, which physically resist penetration by the pathogen (Aust and Hoyningen-Huene 1986). The latter can be limited by non-structural properties, which resist subsequent penetration and nutrient absorption by the pathogen (Aust and Hoyningen-Huene 1986; Bélanger et al. 2002; Pérez-García et al. 2009). Thus, the distinction of these processes by evaluating early hyphal development can reveal the factors that limit pathogen development (Itagaki et al. 2016, 2017). 
The first objective of this study was to evaluate the early development of hyphae on leaves acclimatized to different relative humidities (RHs) so as to investigate the relationships between host-plant susceptibility and leaf properties. The authors focused on leaf mass per area (LMA) and nitrogen $(\mathrm{N})$ content as the leaf properties, because these values correlate respectively with structural and non-structural defense (Walters and Bingham 2007; Toome et al. 2010) and can be altered under water stress conditions (Ben-Zioni et al. 1967; Salleo and Gullo 1990; Yin et al. 2009). The previous study tested seedlings only at the cotyledon stage (Itagaki et al. 2014), whereas the growth stage at which the effects of environmental factors on plant-pathogen interactions are described must be specified (Itagaki et al. 2015). So the second objective was to investigate the effect of acclimatization humidity on conidial development at the true leaf stage.

\section{Materials and Methods}

\section{Expt. 1: Evaluation of early hyphal development of $P$. xanthii on cucumber seedlings} acclimatized to different relative humidities

Cucumber cv. Hokushin (nonresistant cultivar; Takii \& Co. Ltd., Kyoto, Japan) seeds were sown in plastic pots containing vermiculite, which were then placed in growth chambers maintained at a low $(10 \%)$ or high $\mathrm{RH}(90 \%)$ at $30^{\circ} \mathrm{C}$. Illumination was supplied at a photosynthetic photon flux density (PPFD) of $300 \mu \mathrm{mol} \mathrm{m}^{-2} \mathrm{~s}^{-1}$ by fluorescent lamps with a 12-h photoperiod. The pots were placed in nutrient solution (the A-type recipe of OAT Solution; OAT Agrio Co. Ltd., Tokyo, Japan) 10-20 mm deep.

When the cotyledons had expanded and the first true leaf had begun to emerge, seedlings were inoculated. Inoculum was prepared by gently transferring $P$. xanthii conidia on cucumber leaves into distilled water with a brush. The suspension $\left(2.1 \times 10^{6}\right.$ spores $\left.\mathrm{mL}^{-1}\right)$ was then sprayed onto the adaxial surface of the cotyledons with a hand sprayer. The 
83

84

85

86

87

88

89

90

91

92

93

94

95

96

97

98

99

100

101

102

103

104

105

106

107

inoculated seedlings were placed in another growth chamber at $28^{\circ} \mathrm{C}, 50 \% \mathrm{RH}$, and a PPFD of $200 \mu \mathrm{mol} \mathrm{m} \mathrm{s}^{-1}$.

Immediately after acclimatization, 10 uninoculated seedlings were sampled from each RH treatment for evaluation of leaf properties. Dry mass and leaf area were measured, and then LMA was calculated by dividing the dry mass by the leaf area. In addition, the $\mathrm{N}$ contents of the dry matter in each treatment were determined with a CN Elemental Analyzer (2400 II; PerkinElmer Inc., Waltham, MA, USA).

Five inoculated seedlings were sampled at 24, 48 and $72 \mathrm{~h}$ after inoculation, and then conidial invasion, hyphal development, and haustorial formation of $P$. xanthii on their leaves were evaluated according to the methods of Itagaki et al. $(2016,2017)$. The formation of conidial germ tubes and hyphal growth were observed $24 \mathrm{~h}$ after inoculation in each of 50 randomly selected conidia per seedling under an optical microscope (BX-50; Olympus Corp., Tokyo, Japan). The percentage of conidial invasion was calculated as $\Sigma$ (conidia with germ tube and primary hyphae) $\times 100 /\{\Sigma$ (conidia with germ tube only) $+\Sigma$ (conidia with germ tube and primary hyphae)\}. Hyphal growth in each of 30 randomly selected conidia per seedling that had successfully infected leaves were then evaluated as the total number of primary, secondary, and tertiary hyphae (which were formed respectively from conidia, primary hyphae and secondary hyphae) per conidium 24,48 and $72 \mathrm{~h}$ after inoculation. The total number of secondary haustoria and hyphal cells per conidium were also evaluated 24 and $48 \mathrm{~h}$ after inoculation. The number of colonies on the adaxial surface of 10 seedlings in each treatment was counted at $5 \mathrm{~d}$ after inoculation, and then colony density was determined by dividing the number of colonies by the leaf area to evaluate conidial development.

\section{Expt. 2: Inoculation test at the first-true-leaf stage}

Twenty-five seedlings in each RH treatment (10\% and 90\%) were grown as in Expt. 1. When 
108 the first true leaf had expanded and the second true leaf had begun to emerge, the adaxial

109 surface of the first true leaf and cotyledons of 15 seedlings were spray-inoculated in each

110 treatment with a spore suspension $\left(8.4 \times 10^{5}\right.$ spores $\left.\mathrm{mL}^{-1}\right)$. Colony densities on the adaxial

111 surface were determined at $7 \mathrm{~d}$ after inoculation. Immediately after acclimatization, 10

112 uninoculated seedlings were sampled from each RH treatment for evaluation of LMA.

\section{Statistical analysis}

115 In Expt. 1, the differences in leaf properties and hyphal development between treatments were 116 analyzed by Student's $t$-test. In Expt. 2, the effects of RH and leaf type (i.e. cotyledons or true 117 leaves) and their interaction were determined by two-way analysis of variance (ANOVA).

118 Each seedling was considered as a biological replicate. All analyses were performed in Statcel

1192 software (OMS Publishing Inc., Tokorozawa, Japan).

\section{Results}

\section{Expt. 1: Evaluation of early hyphal development}

123 The percentage of conidial invasion on the low-RH leaves $24 \mathrm{~h}$ after inoculation was $\times 0.74$ 124 that of the high-RH leaves (Fig. 1A). The leaves acclimatized to low RH had a higher LMA $125(\times 1.24)$ than high-RH leaves (Table 1$)$. The colony density on the low-RH leaves at $5 \mathrm{~d}$ after 126 inoculation was $\times 0.68$ that on the high-RH leaves (Fig. 1B).

127 The low-RH leaves had fewer primary (Fig. 2A), secondary (Fig. 2B), and tertiary (Fig. 128 2C) hyphae than the high-RH leaves. The numbers of hyphal cells (Fig. 2D) and secondary 129 haustoria (Fig. 2E) per conidium on the low-RH leaves were $\times 0.81$ and $\times 0.72$, respectively, 130 compared to those on the high-RH leaves at $48 \mathrm{~h}$. The leaf $\mathrm{N}$ content of the low-RH leaves 131 was $\times 0.91$ that of the high-RH leaves (Table 1 ). 


\section{Expt. 2: Inoculation test at the first-true-leaf stage.}

134 Conidial development was inhibited on the low-RH leaves at the first-true-leaf stage also (Fig.

$1353 \mathrm{~A})$. The colony densities on the cotyledons and first true leaves acclimatized to low RH were $136 \times 0.39$ and $\times 0.58$ the respective densities on high $\mathrm{RH}$-leaves. There was a significant

137 interaction between acclimatization $\mathrm{RH}$ and leaf type, with a stronger RH effect on cotyledons

138 than on first true leaves as described above. In addition, the effect of RH appeared stronger in

139 the cotyledons at the first-true-leaf stage (Fig. 3A) than in those at the cotyledon stage in

140 Expt. 1 (Fig. 1B). LMA increased at low RH in both leaf types: LMA on cotyledons and first

141 true leaves at low $\mathrm{RH}$ were $\times 1.16$ and $\times 1.28$ the respective LMA at high $\mathrm{RH}$ (Fig. $3 \mathrm{~B}$ ). LMA

142 was greater in cotyledons than in first true leaves, and there was no significant interaction

143 between leaf type and acclimatization $\mathrm{RH}$.

\section{Discussion}

146 In Expt. 1, the lower percentage of conidial invasion on the low-RH leaves (Fig. 1A) means

147 that initial invasion of $P$. xanthii was suppressed on the low-RH leaves. The initial invasion of

$148 \quad$ P. xanthii is generally affected by the structural properties of host leaves (Aust and

149 Hoyningen-Huene 1986). The higher LMA of low-RH leaves (Table 1), which functions to

150 protect plants against water loss (Salleo and Gullo 1990), may correlate with an increase in

151 structural defenses against pathogen invasion (Toome et al. 2010).

152 The difference in post-invasion behaviors of $P$. xanthii between treatments (Fig. 2) 153 suggests that conidial development was also affected by non-structural properties of leaves.

154 The reduced leaf $\mathrm{N}$ content of the low-RH leaves (Table 1) may in part have inhibited the 155 post-invasion behaviors of $P$. xanthii, because reduced $\mathrm{N}$ generally correlated with plant 156 defense through altered leaf nutritional quality (Walters and Bingham 2007). Several reports

157 demonstrated that leaf $\mathrm{N}$ content is positively related to susceptibility to powdery mildews 
158 (Hoffland et al. 2000; Olesen et al. 2003; Neumann et al. 2004). The reduction of leaf N

159 content in the present study was in a range where this would have a significant effect on

160 susceptibility (Hoffland et al. 2000). Leaf $\mathrm{N}$ content possibly decreases under water-stress

161 conditions (Ben-Zioni et al. 1967; Yin et al. 2009). Therefore, the reduction of leaf $\mathrm{N}$ contents

162 by low-RH acclimatization may be caused by moderate water stress due to high evaporative

163 demand, although the true reasons are not elucidated in the present study.

164 In Expt. 2, it was confirmed that low-RH acclimatization inhibits development of $P$.

165 xanthii also at the true leaf stage. The stronger RH effect on colony density in the cotyledons

166 than in the first true leave (Fig. 3A) indicates that effect of low RH on host-plant

167 susceptibility was less on the first true leaf than on the cotyledon. This is probably due to

168 developmental differences between the two types of leaves. In addition, the stronger $\mathrm{RH}$

169 effect in the cotyledons at the first-true-leaf stage (Fig. 3A) than in those at the cotyledon

170 stage (Fig. 1B) may be caused by differences in acclimatization period or leaf maturity,

171 because the cotyledons were already older than the first true leaves. The greater LMA of low-

172 RH leaves (Table 1, Fig. 3B) may have partially explain these differences. However,

173 relationships between LMA and host-plant susceptibility were not consistent between leaf

174 types; the difference in LMA between low and high RH was larger for first true leaves than

175 for the cotyledons, whereas the difference in colony density was greater in the cotyledons

176 (Fig. 3). This implies that plant susceptibility to $P$. xanthii cannot be explained only by leaf

177 structural properties, and that one or more other factors such as the nutrient components limit

178 pathogen development.

179 In conclusion, both the initial and the post invasion behavior of $P$. xanthii were inhibited 180 on the leaves acclimatized to low RH, suggesting that conidial development was affected by

181 both structural and non-structural properties of host plant leaves. The main findings and 182 experimental approach in the present study could be used effectively in future studies to 
183 clarify the roles of atmospheric humidity in determining plant-pathogen interactions.

184

\section{Acknowledgement}

186 This research was supported by a Grant-in-Aid for Japan Society for the Promotion of Science 187 (JSPS) Fellows (No. 2510391) and a Grant-in-Aid for Scientific Research (B) (No. 188 15H04575) from JSPS. K. Itagaki was a research fellow of Japan Society for the Promotion of 189 Science (2013-2016). The authors are grateful to Dr. Yukio Sato for technical advice, and 190 Motoaki Tojo for helpful suggestions.

\section{References}

193 Aust, H., and Hoyningen-Huene, J.V. 1986. Microclimate in relation to epidemics of powdery 194 mildew. Ann. Rev. Phytopathol. 24: 491-510.

195 Bélanger, R. R., Bushnell, W. R., Dik, A. J., and Carver, T. L. 2002. The powdery mildews: 196 A comprehensive treatise. St. Paul: APS Press.

197 Ben-Zioni, A., Itai, C., and Vaadia, Y. 1967. Water and salt stresses, kinetin and protein 198 synthesis in tobacco leaves. Plant Physiol. 42: 361-365.

199 Hoffland, E., Jeger, M.J., and van Beusichem, M.L. 2000. Effect of nitrogen supply rate on 200 disease resistance in tomato depends on the pathogen. Plant and Soil, 218: 239-247.

201 Itagaki, K., Sato, Y., and Tojo, M. 2017. Resistance levels of cucumber to Podosphaera 202 xanthii in a growth chamber are related to haustorial formation and hyphal branching 203 frequency. J. Gen. Plant Pathol. 83: 310-315

204 Itagaki, K., Shibuya, T. Tojo, M., Endo, R., and Kitaya, Y. 2014. Atmospheric moisture 205 influences on conidia development in Podosphaera xanthii through host-plant 206 morphological responses. Eur. J. Plant Pathol. 138: 113-121.

207 Itagaki, K., Shibuya, T., Tojo, M., Endo, R., and Kitaya, Y. 2015. Development of powdery 
mildew fungus on cucumber leaves acclimatized to different $\mathrm{CO}_{2}$ concentrations. HortScience, 50: 1662-1665.

210 Itagaki, K., Shibuya, T., Tojo, M., Endo, R., and Kitaya, Y. 2016. Early development of

211 powdery mildew on cucumber leaves acclimatized to illumination with different red-to-

212 far-red ratios. HortScience, 51: 530-536.

213 Neumann, S., Paveley, N.D., Beed, F.D., and Sylvester-Bradley, R. 2004. Nitrogen per unit

214 leaf area affects the upper asymptote of Puccinia striiformis f. sp. tritici epidemics in $215 \quad$ winter wheat. Plant Pathol. 53:725-732.

216 Olesen, J.E., Jørgensen, L.N., Petersen, J., and Mortensen, J.V. 2003. Effects of rate and 217 timing of nitrogen fertilizer on disease control by fungicides in winter wheat. 1. Grain 218 yield and foliar disease control. J. Agr. Sci. 140: 1-13.

219 Pérez-García A, Romero, D., Fernández-Ortuño, D., López-Ruiz, F., De Vicente, A., and 220 Tores, J.A. 2009. The powdery mildew fungus Podosphaera fusca (synonym 221 Podosphaera xanthii), a constant threat to cucurbits. Mol. Plant Pathol. 10: 153-160.

222 Reuveni, R., and Rotem, J. 1974. Effect of humidity on epidemiological patterns of the 223 powdery mildew (Sphaerotheca fuliginea) on squash. Phytoparasitica, 2: 25-33.

224 Salleo, S., and Gullo, M.L. 1990. Sclerophylly and plant water relations in three 225 Mediterranean Quercus species. Ann. Bot. 65: 259-270.

226 Toome, M., Heinsoo, K., and Luik, A. 2010. Relation between leaf rust (Melampsora epitea) 227 severity and the specific leaf area in short rotation coppice willows. Eur. J. Plant Pathol. $228 \quad$ 126: $583-588$.

229 Walters, D.R., and Bingham, I.J. 2007. Influence of nutrition on disease development caused 230 by fungal pathogens: implications for plant disease control. Ann. Appl. Biol. 151: 307$231 \quad 324$.

232 Yarwood, C.E. 1957. Powdery mildew. Bot. Rev. 23: 235-301. 
233 Yin, C., Pang, X., and Chen, K. 2009. The effects of water, nutrient availability and their 234 interaction on the growth, morphology and physiology of two poplar species. Environ. 235 Exp. Bot. 67: 196-203. 
236 Table 1 Leaf mass per area (LMA) and leaf nitrogen $(\mathrm{N})$ contents of cucumber cotyledons

237 acclimatized to low (10\%) or high (90\%) relative humidity (RH) in Expt. 1.

\begin{tabular}{lll}
\hline Treatment & $\begin{array}{l}\text { LMA } \\
\left(\mathrm{mg} \mathrm{cm}^{-2}\right)\end{array}$ & $\begin{array}{l}\text { Leaf N content } \\
(\% \mathrm{DW})\end{array}$ \\
\hline Low RH & $2.45 \pm 0.07$ & $7.12 \pm 0.08$ \\
High RH & $1.98 \pm 0.05$ & $7.79 \pm 0.08$ \\
\hline$P$ value & $<0.001$ & $<0.001$
\end{tabular}

$238 \quad \overline{M e a n} \pm \operatorname{SE}(n=10)$.

$239 P$ values were determined by Student's $t$-test. 


\section{$240 \quad$ Figure captions}

241 Fig. 1 (A) Initial conidial invasion of $P$. xanthii $24 \mathrm{~h}$ after inoculation $(n=5)$ and (B) colony

242 density $5 \mathrm{~d}$ after inoculation $(n=10)$ on cucumber leaves acclimatized to either a low $(10 \%)$

243 or high $(90 \%)$ relative humidity $(\mathrm{RH})$ in Expt. 1. Error bars represent SE. $P$ values were

244 determined by Student's $t$-test.

245

246 Fig. 2 Numbers of (A) primary, (B) secondary, and (C) tertiary hyphae, (D) total number of 247 hyphal cells, and (E) number of secondary haustoria of $P$. xanthii on cucumber seedlings 248 acclimatized to either low $(10 \%)$ or high $(90 \%)$ relative humidity $(\mathrm{RH})$ in Expt. $1(n=5)$.

249 Differences between treatments are significant at $* P=0.05, * * P=0.01, * * * P=0.001$ by 250 Student's $t$-test; NS, not significant $(P>0.05)$.

251

252 Fig. 3 (A) Colony density of $P$. xanthii on cotyledons and first true leaves in cucumber 253 seedlings acclimatized to either low (10\%) or high $(90 \%)$ relative humidity (RH) 7 days after 254 inoculation $(n=15)$, and (B) leaf mass per area (LMA) of host plants before inoculation $(n$ $255=10$ ) in Expt. 2. Error bars represent SE. Spores were inoculated on cotyledons and first true 256 leaves when the first true leaves were fully expanded. The effects of RH and leaf type and 257 their interaction were determined by two-way analysis of variance (ANOVA). 


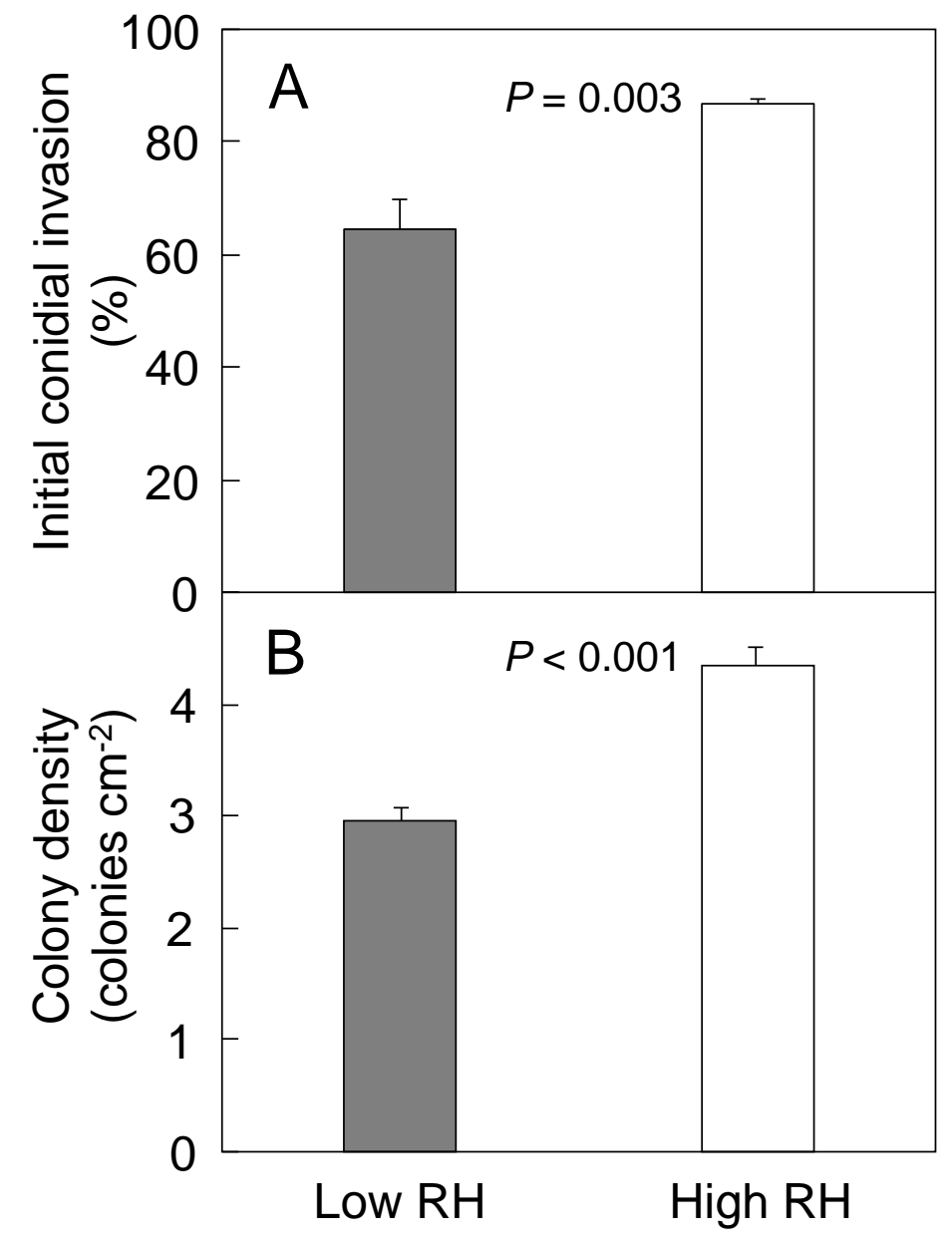

Fig. 1 


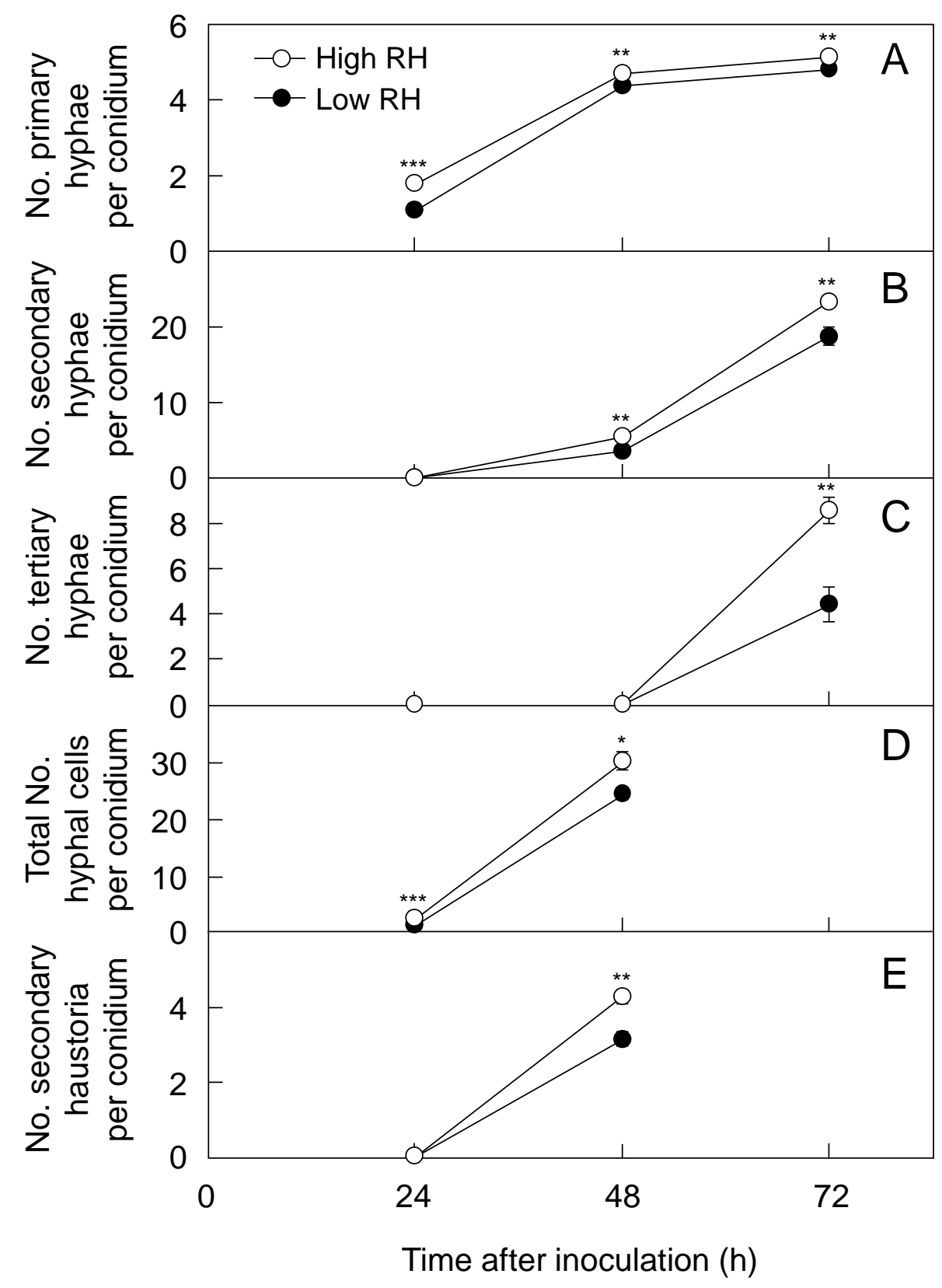

Fig. 2 


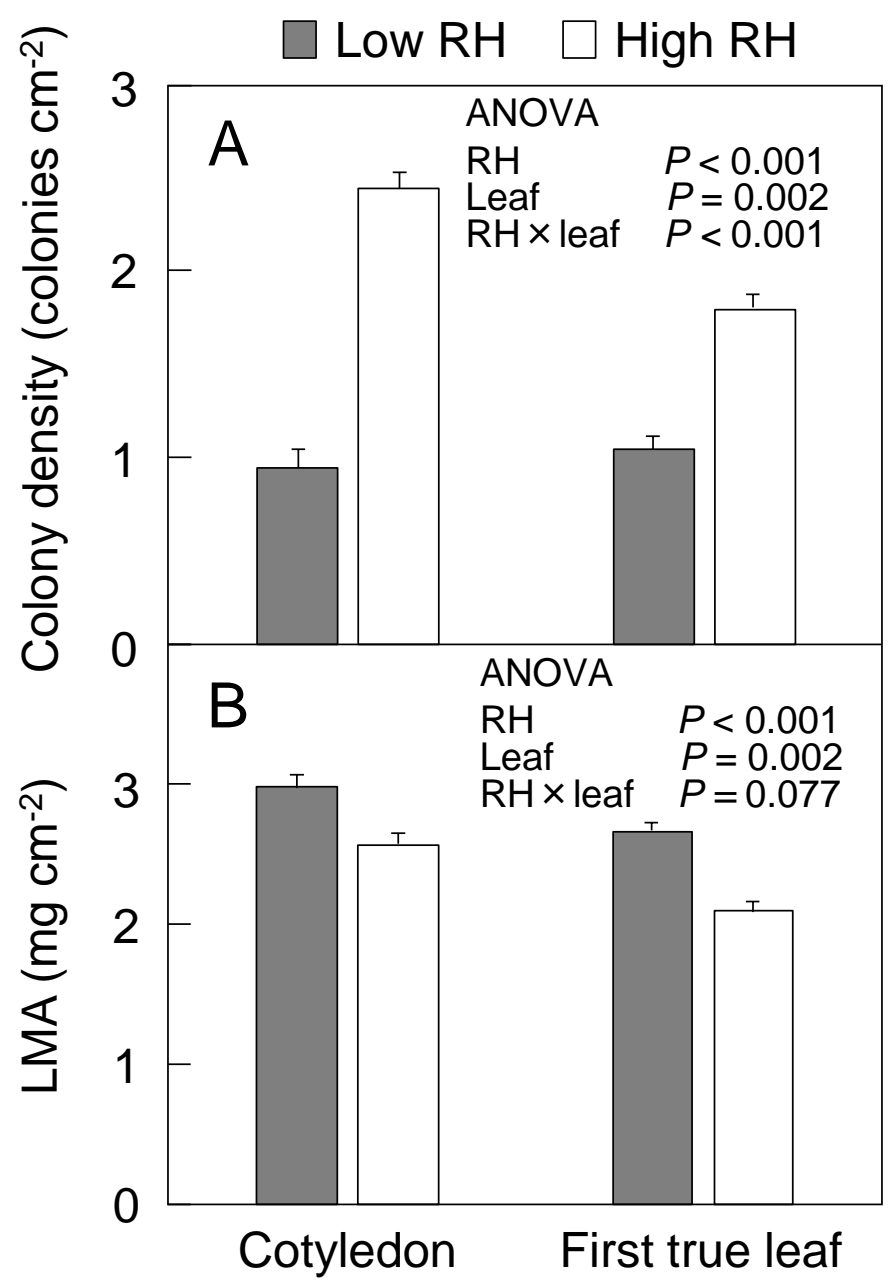

Fig. 3 